REVISTA DE DERECHO UNED, NÚM. 19, 2016

\title{
LA INFORMACIÓN PRECONTRACTUAL EN EL ÁMBITO DE LOS VIAJES COMBINADOS TRAS LA DIRECTIVA (UE) 2015/2302 DEL PARLAMENTO EUROPEO Y DEL CONSEJO, DE 25 DE NOVIEMBRE DE 2015, RELATIVA A LOS VIAJES COMBINADOS Y A LOS SERVICIOS DE VIAJE VINCULADOS
}

PRE-CONTRACTUAL INFORMATION IN THE SCOPE OF THE PACKAGE TRAVEL AFTER THE DIRECTIVE (EU) 2015/2302 OF THE EUROPEAN PARLIAMENT AND OF THE COUNCIL, 25 NOVEMBER 2015, ON PACKAGE TRAVEL AND LINKED TRAVEL ARRANGEMENTS

\section{Consuelo CAmacho Pereira}

Doctora por el Dpto. Derecho Civil de la Facultad de Derecho de la UNED

Profesora de Derecho Civil en el Centro Universitario San Isidoro, adscrito a la Universidad Pablo de Olavide, de Sevilla

Resumen: La Directiva (UE) 2015/2302 del Parlamento Europeo y del Consejo, de 25 de noviembre de 2015, relativa a los viajes combinados y a los servicios de viaje vinculados, ha ampliado el ámbito de aplicación de la normativa de los viajes combinados atendiendo a que actualmente internet se ha convertido en un medio cada vez más importante a través del que se ofrecen o venden servicios de viaje y a que los servicios de viaje, no sólo se combinan en forma de viajes combinados preestablecidos tradicionales, sino que, con frecuencia, se combinan a medida. El presente trabajo se centra en el estudio de los deberes de información precontractual que impone la Directiva en este 
nuevo ámbito, distinguiendo entre una información normalizada y una información más específica en relación con el viaje contratado, con el objetivo de conocer el tratamiento de la integración de tal información en el contrato, y los requisitos exigidos para que las modificaciones en dicha información sean oponibles al viajero: que las partes contratantes lo acuerden expresamente, habiéndose comunicado todos los cambios en la información precontractual al viajero, de forma clara, comprensible y destacada, antes de contratar el viaje combinado.

Abstract: The Directive (EU) 2015/2302 of the European Parliament and of the Council, 25 november 2015, on package travel and linked travel arrangements, has expanded the scope of the package travel regulations, because actually, the internet has become an increasingly important medium through which travel services are offered or sold, and travel services are not only combined in the form of traditional pre-arranged packages, but are often combined in a customised way. This paper focuses on the study of the duties of pre-contractual information imposed by the Directive in this new field, distinguishing between standardized information and more specific information in relation to the contracted trip, with the aim of knowing the treatment of integration of such information in the contract and the requirements for changes in such information are opposable traveler: the contracting parties expressly agree, having communicated all changes to the pre-contractual information to the traveller in a clear, comprehensible and prominent before the conclusion of the package travel contract.

Palabras clave: Viajes combinados, información precontractual, contrato a distancia, viajero.

Keywords: Package travel, pre-contractual information, distance contract, traveler.

Recepción original: 17/06/2016.

Aceptación original: 10/10/2016.

Sumario: I. Introducción. II. Justificación de la DVCSVV. III. Ámbito de aplicación, III.A. Los servicios de viaje, III.B. Viajes combinados, III.C. Servicios de viajes vinculados, III.D. Exclusiones del ámbito de aplicación de la DVCSVV; IV. Sujetos en el contrato de viaje combinado. $\mathrm{V}$. La información precontractual al viajero en la DVCSVV. V.A. Contenido y caracteres de la información precontractual al viajero en la DVCSVV, V.B. Carácter vinculante de la informa- 
ción precontractual en los viajes combinados. V.B.1. Regulación y antecedentes del carácter vinculante de la información precontractual en los viajes combinados. V.B.2. La integración de la información precontractual en el contrato de viajes combinados.

\section{INTRODUCCIÓN}

Con fecha 25 de noviembre de 2015, se aprobó la Directiva (UE) 2015/2302, del Parlamento Europeo y del Consejo, relativa a los viajes combinados y a los servicios de viaje vinculados, por la que se modifican el Reglamento (CE) n. ${ }^{\circ}$ 2006/2004 y la Directiva 2011/83/UE del Parlamento Europeo y del Consejo y por la que se deroga la Directiva 90/314/CEE del Consejo ${ }^{1}$ (en adelante, DVCSVV) ${ }^{2}$.

La DVCSVV debe ser traspuesta por los Estados miembros a más tardar el 1 de enero de 2018, y las disposiciones que se aprueben se aplicarán a partir del 1 de julio de 2018³. En el caso de España, dicha trasposición conllevaría la modificación del Libro IV del Real Decreto Legislativo 1/2007, de 16 de noviembre, por el que se aprueba el texto refundido de la Ley General para la Defensa de los Consumidores y Usuarios y otras leyes complementarias (en adelante, TRLGDCU) ${ }^{4}$.

En la DVCSVV se distingue entre «viaje combinado» $\mathrm{y}$ «servicio de viaje vinculado», existiendo distintas obligaciones para los empresarios y derechos para los viajeros, en uno u otro caso. En particular, cuando estemos ante un viaje combinado, el organizador del viaje será el responsable de la ejecución de los servicios de viaje incluidos en el contrato de viaje combinado, sin perjuicio de que la normativa interna de cada Estado pueda atribuir también responsabilidad al minorista ${ }^{5}$, y de que, en cualquier caso, el minorista responda junto al

1 DOUE núm. 326, de 11 de diciembre de 2015, páginas 1 a 33.

2 Como antecedentes de la DVCSVV, el 9 de julio de 2013, se aprobó la Propuesta de Directiva del Parlamento Europeo y del Consejo relativa a los viajes combinados y los servicios asistidos de viaje [COM (2013) 512 final], así como la Comunicación de la Comisión titulada «Adaptar la normativa europea sobre viajes combinados a la era digital» [COM (2013) 513 final]. El 6 de septiembre de 2013, el Consejo consultó al Comité Económico y Social, que emitió su dictamen el 11 de diciembre de 2013. El 19 de septiembre de 2013, el Consejo consultó al Comité de las Regiones, que optó por no emitir dictamen. El Parlamento Europeo aprobó su posición en primera lectura el 12 de marzo de 2014, proponiendo 132 enmiendas a la propuesta de la Comisión.

3 Art. 28 DVCSVV.

${ }^{4}$ BOE núm. 287, de 30-11-2007.

${ }_{5}^{5}$ En relación con la responsabilidad por la ejecución del viaje, se ha dejado a la decisión de cada Estado, la posibilidad de que puedan mantener o establecer en su 
organizador de facilitar información precontractual al viajero ${ }^{6}$ o de errores en la reserva, salvo que sean imputables al viajero o a circunstancias inevitables o extraordinarias ${ }^{7}$. El organizador, y, en su caso, el minorista, debe constituir una garantía que permita reembolsar los pagos de los viajeros, si los servicios no se han ejecutado por su insolvencia, y una garantía para la repatriación de los viajeros si el transporte de pasajeros está incluido en el viaje combinado ${ }^{8}$.

En el caso de los servicios de viaje vinculados, se obliga a los empresarios que faciliten dichos servicios a informar al viajero de que no está contratando un viaje combinado, y de que los responsables de la correcta ejecución de sus contratos son los prestadores de cada servicio. Los empresarios que facilitan los servicios de viaje vinculados deben constituir garantía para reembolso de los pagos que reciban de los viajeros, si un servicio de viaje que forme parte de unos servicios de viajes vinculados no se ejecuta como consecuencia de la insolvencia del empresario, y si dichos empresarios son la parte responsable del transporte de pasajeros, la garantía cubre también su repatriación ${ }^{9}$.

Aún cuando son numerosas las cuestiones que plantea la nueva regulación de los viajes combinados y servicios de viaje vinculados, en el presente trabajo nos centraremos en delimitar el tratamiento de la información precontractual en el supuesto de contratación de viajes combinados. Antes de tratar este tema, sin embargo, conviene delimitar con mayor claridad el ámbito de aplicación de la DVCSVV, para posteriormente determinar qué información ha de suministrarse al

derecho nacional disposiciones que estipulen que también el minorista y no sólo el organizador es responsable de la ejecución del viaje combinado (Art.13.1 DVCSVV). En España el TRLGDCU, considera la responsabilidad solidaria de organizador y detallista frente al consumidor, en el art. 162:«1. Los organizadores y los detallistas de viajes combinados responderán frente al consumidor y usuario, en función de las obligaciones que les correspondan por su ámbito respectivo de gestión del viaje combinado, del correcto cumplimiento de las obligaciones derivadas del contrato, con independencia de que éstas las deban ejecutar ellos mismos u otros prestadores de servicios, y sin perjuicio del derecho de los organizadores y detallistas a actuar contra dichos prestadores de servicios.

La responsabilidad frente al consumidor será solidaria de cuantos empresarios, sean organizadores o detallistas, concurran conjuntamente en el contrato cualquiera que sea su clase y las relaciones que existan entre ellos, sin perjuicio del derecho de repetición de quien responda ante el consumidor y usuario frente a quien sea imputable el incumplimiento o cumplimiento defectuoso del contrato en función de su respectivo ámbito de gestión del viaje combinado».

${ }^{6}$ Art. 5.1. DVCSVV.

7 Art. 21 DVCSVV.

8 Art. 17 DVCSVV.

9 Art. 19 y Considerando Cuarenta y tres DVCSVV. 
viajero antes de contratar, y cómo se integra tal información y sus modificaciones en el contrato.

Para llevar a cabo este trabajo, hemos partido del articulado de la DVCSVV, así como de su comparación con la Directiva que deroga y con nuestro derecho interno; a lo largo del mismo, podrá observarse la existencia de continuas referencias a los considerandos de la DVCSVV, a los que hay que acudir con frecuencia para aclarar el sentido de su articulado, ya que aunque no tienen carácter vinculante, son imprescindibles en la interpretación de la Directiva objeto de estudio $^{10}$.

\section{JUSTIFICACIÓN DE LA DVCSVV}

La aprobación de la DVCSVV se justifica por la necesidad de "adaptar el marco legislativo a la evolución del mercado para adecuarlo mejor al mercado interior, eliminar ambigüedades y colmar las lagunas legislativas» ${ }^{11}$.

La Exposición de Motivos de la Propuesta de Directiva del Parlamento Europeo y del Consejo relativa a los viajes combinados y los servicios asistidos de viaje ${ }^{12}$, justificaba la nueva regulación atendiendo al desarrollo de la distribución por Internet y liberalización del sector del transporte aéreo, que han cambiado la manera en que los consumidores organizan sus vacaciones, originando diferentes formas en que los operadores ayudan a los consumidores a personalizar las combinaciones de servicios de viajes, en particular en línea ${ }^{13}$. Por

10 Comunicación a los miembros de la Comisión de Peticiones del Parlamento Europeo (2014-2019), 28.2.2015.

11 Considerando Primero de la DVCSVV.

12 COM (2013) 512 final, 12.7.2013.

${ }^{13}$ En este sentido, la Comunicación de la Comisión al Parlamento Europeo, al Consejo, al Comité Económico y Social Europeo y al Comité de las Regiones, "Adaptar la normativa europea sobre viajes combinados a la era digital», COM (2013) 513 final, 9.7.2013, señaló que el mercado de viajes se ha transformado, especialmente desde la introducción de Internet. La regulación de nuevas combinaciones de servicios de viaje afectará a cerca del 50\% del mercado y se debería reforzar la confianza y la satisfacción de los viajeros. Sólo en el mes de marzo de 2013, casi 183 millones de ciudadanos visitaron un sitio web de viajes en línea. El mercado de viajes también se ha transformado por la liberalización del sector del transporte aéreo, que ha abaratado y hecho más accesibles los billetes de avión. Gómez Calle deja en evidencia que: "La Directiva 90/314 es en estos momentos la más antigua en materia de derecho de consumo y ante el cambio que genera Internet y el comercio electrónico en el mercado de los viajes requiere ser revisada y actualizada». GómEz CALLE, E.: «En torno a una posible revisión del régimen del viaje combinado», en La revisión de las normas europeas y nacionales de protección de los consumidores. Más allá de la Directiva sobre de- 
tanto, uno de los principales objetivos de la DVCSVV, es adaptarse a la contratación de viajes on line y a nuevas modalidades de combinación de los viajes. El «e-turista» desea flexibilización a la hora de confeccionar su viaje, quiere elegir sus propios destinos, lugares de estancia y tiempo de duración. A esta nueva forma de contratación de servicios turísticos se la conoce como paquetes dinámicos de turismo, viajes flexibles o dynamic packages ${ }^{14}$.

En el mismo sentido que la Propuesta de Directiva, el Considerando Segundo de la DVCSVV, señala que: "... hay que tener en cuenta que además de las cadenas de distribución tradicionales, internet se ha convertido en un medio cada vez más importante a través del que se ofrecen o venden servicios de viaje, y que los servicios de viaje no sólo se combinan en forma de viajes combinados preestablecidos tradicionales, sino que con frecuencia se combinan a medida. Muchas de esas combinaciones de servicios de viaje quedaban en una situación de indefinición jurídica o no se encontraban, al menos, claramente incluidos dentro del ámbito de aplicación de la Directiva 90/314/CEE, por lo que la nueva Directiva tiene por objeto adaptar el alcance de la protección para tener en cuenta esta evolución, aumentar la transparencia y la seguridad jurídica de los viajeros y empresarios».

La Propuesta de Directiva justificaba también la reforma por el perjuicio que causaba al consumidor la existencia de normas confusas y obsoletas. El interesante estudio "Consumer Detriment Study in the area of Dynamic Packages ${ }^{15}$ calculó el perjuicio causado al consumidor por los servicios combinados de viaje cuando la aplicación de la anterior Directiva era incierta, como en el caso de los paquetes dinámicos de viajes combinados ${ }^{16}$. Este estudio puso de manifiesto que los problemas con estos servicios de viaje son cada vez más frecuentes y más perjudiciales para los consumidores que los problemas relacio-

rechos de los consumidores y del Instrumento opcional sobre un Derecho Europeo de la Compraventa de octubre de 2011. Cámara Lapuente, S/ArRoyo i Amayuelas, E. (Coords.), Ed. Civitas Thomson Reuters, Madrid, 2012, pág. 385.

${ }^{14}$ Camargo Gómez, J. D., "Contratación electrónica de paquetes dinámicos de turismo en el ordenamiento jurídico español». Ars Iuris Salmanticensis: AIS: Revista europea e iberoamericana de pensamiento y análisis de derecho, ciencia política y criminología, vol. 2, n. ${ }^{\circ}$ 2, 2014, pág. 96.

15 http://ec.europa.eu/consumers/archive/rights/docs/study_consumer_detriment_ dyna_packages_en.pdf The European Commission - Health and Consumers DG. Preparado por London Economics, Noviembre, 2009.

${ }_{16}$ Este estudio mide el perjuicio atendiendo al resultado negativo respecto de algún indicador de referencia, como las expectativas razonables. Se centra en los resultados a posteriori para los consumidores que han tenido una experiencia negativa con los viajes, incluyendo los perjuicios patrimoniales y morales, en particular la pérdida de tiempo. 
nados con los viajes combinados tradicionales, que están claramente cubiertos por la anterior Directiva, y que existe una creencia del consumidor de que puede reclamar a quien considera vendedor en la compra del paquete dinámico.

Asimismo, el art. 1 de la DVCSVV, que delimita su objeto, considera que se trata con la misma de: «Contribuir al buen funcionamiento del mercado interior y a la consecución de un nivel de protección de los consumidores elevado ${ }^{17}$ y lo más uniforme posible mediante la aproximación de determinados aspectos de las disposiciones legales, reglamentarias y administrativas de los Estados miembros en relación con los contratos entre viajeros y empresarios relativos a viajes combinados y a servicios de viaje vinculados» ${ }^{18}$.

\section{III. ÁMBITO DE APLICACIÓN}

Uno de los aspectos más complejos de la DVCSVV es la delimitación de su ámbito de aplicación, al que se refiere su artículo 2, y que abarca: Viajes combinados ofrecidos para la venta; viajes combinados vendidos por empresarios a viajeros ${ }^{19}$; y servicios de viaje vinculados

${ }^{17}$ El Considerando Tres de la DVCSVV, se refiere como punto de partida al artículo 169, apartados 1 y 2, letra a), del Tratado de Funcionamiento de la Unión Europea (TFUE) que establece que la Unión contribuirá a la consecución de un alto nivel de protección de los consumidores mediante las medidas que adopte en virtud de su artículo 114. Sin embargo, para evitar la confusión con la definición del término «consumidor» utilizado en otros actos legislativos de la Unión, se refiere a las personas amparadas por la presente Directiva como «viajeros», concepto que, como veremos, es más amplio que el que utiliza la normativa europea para referirse al consumidor.

${ }_{18}$ En este sentido, los Considerandos Cuatro, Cinco y Seis, justifican la nueva Directiva en que la Directiva 90/314/CEE dejaba un amplio margen de apreciación a los Estados miembros para su transposición, razón por la cual subsisten divergencias significativas en su legislación. La fragmentación jurídica supone mayores costes para las empresas y obstáculos para los empresarios que desean desarrollar actividades transfronterizas, limitando de este modo las opciones de los consumidores, siendo necesario armonizar los derechos y obligaciones que se derivan de los contratos relativos a los viajes combinados y a los servicios de viaje vinculados para crear un auténtico mercado interior de los consumidores en este ámbito.

19 Aclara el Considerando Ocho DVCSVV, que: "Dado que los servicios de viaje pueden combinarse de muy distintas maneras, conviene considerar como viajes combinados todas las combinaciones de servicios de viaje que presenten las características que los viajeros asocian normalmente a tales viajes, en particular, cuando distintos servicios de viaje se combinan en un único producto de viaje de cuya correcta ejecución asume la responsabilidad el organizador. De conformidad con la jurisprudencia del Tribunal de Justicia de la Unión Europea (Véase la sentencia del Tribunal de Justicia de la Unión Europea de 30 de abril de 2002, Club Tour, Viagens e Turismo SA/Alberto Carlos Lobo Gonçalves Garrido y Club Med Viagens Ld.a, C-400/00, ECLI: EU: C:2002:272), no debe haber diferencia entre la combinación de los servicios de viaje previa a cualquier contac- 
facilitados por empresarios a viajeros, cuyo régimen no es totalmente coincidente con los anteriores.

Para el correcto entendimiento de este artículo, debemos acudir a las definiciones que proporciona el art. 3 DVCSVV, siendo fundamentales las relativas a "servicio de viaje», "viajes combinados», $\mathrm{y}$ "servicios de viaje vinculados», que no hacen más que delimitar el ámbito de aplicación de la Directiva.

\section{III.A. Los servicios de viaje}

Podemos decir que el "servicio de viaje» es cada una de las partes de un viaje que, según quién las combine, cómo se presenten, cómo se combinen, y cómo se contraten, puede originar un viaje combinado, unos servicios de viajes vinculados o una mera yuxtaposición de servicios de viaje, teniendo cada uno de estos supuestos una regulación diferente. El mencionado art. 3 DVCSVV, en el apartado 1 considera como «servicio de viaje»:

a) el transporte de pasajeros;

b) el alojamiento cuando no sea parte intrínseca del transporte de pasajeros y no tenga fines residenciales ${ }^{20}$;

c) alquiler de turismos, otros vehículos de motor en el sentido del artículo 3, punto 11, de la Directiva 2007/46/CE del Parlamento Europeo y del Consejo ${ }^{21}$, o motocicletas que requieran un permiso de conducción de categoría A con arreglo a lo dispuesto en el artículo 4, apartado 3, letra c), de la Directiva 2006/126/CE del Parlamento Europeo y del Consejo;

d) cualquier otro servicio turístico que no forme parte intrínseca de un servicio de viaje de los definidos en las letras a), b) o c)».

Es preciso acudir a los Considerandos de la DVCSVV para aclarar qué servicios turísticos pueden considerarse que están o que no están intrínsecamente incluidos en los definidos en las letras a), b) o c) an-

to con el viajero, o a petición del viajero o según la selección realizada por este. Deben aplicarse los mismos principios con independencia de que la reserva se efectúe a través de un empresario que atiende a sus clientes de manera presencial o en línea».

${ }^{20}$ Considerando 17 DVCSVV: "El alojamiento con fines residenciales, incluido el alojamiento para cursos de idiomas de larga duración, no debe considerarse alojamiento a efectos de la presente Directiva».

21 "11) "vehículo de motor": todo vehículo autopropulsado que se mueva por sus propios medios, que tenga por lo menos cuatro ruedas, ya sea completo, completado o incompleto, y con una velocidad máxima de diseño superior a $25 \mathrm{~km} / \mathrm{h}$.» 
teriores. El Considerando Dieciocho se refiere a título de ejemplo, como servicios que no están intrínsecamente incluidos en los definidos en las letras a), b) o c), a las «entradas para conciertos, acontecimientos deportivos, excursiones o parques de atracciones, las visitas guiadas, los forfaits de esquí y el alquiler de material deportivo, por ejemplo de esquí, o los tratamientos balnearios». Por su parte, el Considerando Diecisiete incluye a título de ejemplo, entre los servicios que forman parte intrínseca de otro servicio de viaje y que no deben considerarse servicios de viaje en sí mismos: «... el transporte de equipaje realizado como parte del transporte de viajeros, pequeños servicios de transporte, como el traslado de los pasajeros como parte de una visita guiada o los traslados entre un hotel y un aeropuerto o estación de ferrocarril, las comidas, las bebidas y los servicios de limpieza facilitados como parte del servicio de alojamiento, o el acceso a instalaciones del hotel como piscinas, saunas, balnearios o gimnasios incluidos en el alojamiento para los viajeros alojados en el hotel. Esto significa asimismo que si, a diferencia de lo que ocurre en los cruceros, se ofrece la pernoctación como parte del transporte de viajeros por carretera, ferrocarril, barco o avión, el alojamiento no debe considerarse en sí mismo un servicio de viaje si el elemento principal es claramente el transporte».

\section{III.B. Viaje combinado}

Una vez definidos los «servicios de viaje», el apartado 2 del art. 3 DVCSVV, considera al "viaje combinado», como la combinación de al menos dos tipos de servicios de viaje a efectos del mismo viaje o vacación, si esos servicios:

a) son combinados por un solo empresario, incluso a petición o según la selección del viajero, antes de que se celebre un contrato único por la totalidad de los servicios, $o$

b) con independencia de la celebración de contratos distintos con diferentes prestadores de servicios de viaje, esos servicios:

i) son contratados en un único punto de venta ${ }^{22}$ y han sido seleccionados antes de que el viajero acepte pagar ${ }^{23}$,

${ }^{22} \mathrm{El}$ art. $3.15 \mathrm{DVCSVV}$ considera "punto de venta»: "todo local de venta al por menor, tanto mueble como inmueble, o un sitio web de venta minorista o un dispositivo de venta minorista en linea similar, incluso cuanto los sitios web de venta minorista o dispositivos de venta minorista en línea se presenten a los viajeros como un dispositivo único, incluido un servicio telefónico».

${ }_{23}$ El Considerando Diez DVCSVV se refiere a que se contrata en base al «mismo proceso de reserva». 
ii) son ofrecidos o facturados a un precio a tanto alzado o global,

iii) son anunciados o vendidos como «viaje combinado» o bajo una denominación similar ${ }^{24}$,

iv) son combinados después de la celebración de un contrato en virtud del cual el empresario permite al viajero elegir entre una selección de distintos tipos de servicios de viaje ${ }^{25}$,

v) son contratados con distintos empresarios a través de procesos de reserva en línea conectados en los que el nombre del viajero, sus datos de pago y su dirección de correo electrónico son transmitidos por el empresario con el que se celebra el primer contrato a otro u otros empresarios, con el o los que se celebra un contrato a más tardar 24 horas después de la confirmación de la reserva del primer servicio de viaje».

El apartado a) del artículo 3.2 DVCSVV coincide con el concepto de viaje combinado de la anterior Directiva 90/314/CEE del Consejo y con la interpretación que venía haciendo el TJUE. Los restantes supuestos, obedecen a la intención de la DVCSVV manifestada en su Considerando Ocho, de ampliar su aplicación a «todas las combinaciones de servicios de viaje que presenten las características que los viajeros asocian normalmente a tales viajes», tanto si se adquieren en un solo contrato, como si se adquieren a través de varios contratos con distintos prestadores. En todos estos casos estamos ante «contrato de viaje combinado", definido en el art. 3.3 DVCSVV como: «el contrato por el conjunto del viaje combinado o, si dicho viaje se realiza con arreglo a contratos distintos, todos los contratos que regulen los servicios de viaje incluidos en el viaje combinado». Por tanto, la DVCSVV llega a considerar "contrato» a varios contratos conexos, en atención a que el viajero, por lo general, no tiene conciencia de que ha suscrito varios contratos, o puede considerar responsable a la entidad que aparece como perceptora del pago $^{26} \mathrm{O}$ como organizadora del viaje en su conjunto.

Este mismo artículo 3.2 DVCSVV excluye de la consideración de viajes combinados las combinaciones de servicios de viaje en las que

${ }^{24}$ Según el Considerando Diez de la DVCSVV: "Dicha denominación podría ser, por ejemplo, "oferta combinada», "todo incluido» o "paquete turístico o vacacional».

${ }^{25}$ En el Considerando Once se señala como ejemplo el caso de una "caja regalo» para un viaje combinado.

${ }^{26}$ El estudio "Consumer Detriment Study in the area of Dynamic Packages», señala que el $80 \%$ de consumidores que usaron los paquetes dinámicos pensaron que estaba incluida la protección financiera. 
se combine como máximo uno de los tipos de servicio de viaje a que se refiere el punto 1 , letras a), b) o c), con uno o varios de los servicios turísticos a que se refiere el punto 1, letra d), si estos servicios turísticos:

«a) No representan una proporción significativa del valor de la combinación y no se anuncian como una característica esencial de la combinación ni constituyen por alguna otra razón una característica esencial de esta ${ }^{27} \mathrm{o}$

b) sólo han sido seleccionados y contratados después de que se haya iniciado la ejecución de un servicio de viaje contemplado en el punto 1 , letras $a$ ), $b$ ) o c)»

\section{III.C. Servicios de viajes vinculados}

La DVCSVV ha regulado en el art. 3.5 los llamados «servicios de viajes vinculados», a los que nos referiremos brevemente, por la dificultad de su delimitación de determinados viajes $\operatorname{combinados}^{28}$. Se consideran tales "al menos dos tipos diferentes de servicios de viaje contratados para el mismo viaje o vacación, para los que se celebren contratos distintos con cada uno de los prestadores de servicios de viaje, si un empresario facilita:

a) Con ocasión de una única visita o contacto con su punto de venta, la selección y pago por separado de cada servicio de viaje por parte de los viajeros ${ }^{29} »$. No siempre será fácil delimitar este supuesto del viaje

${ }^{27}$ A nuestro parecer, siguiendo la literalidad de la DVCSVV, tales requisitos han de cumplirse de forma cumulativa, aunque el Considerando Dieciocho de la DVCSVV los contempla como alternativos. Por otra parte, según el mencionado Considerando: «... si otros servicios turísticos representan el $25 \%$ o más del valor de la combinación, debe considerarse que constituyen una proporción significativa del valor del viaje combinado o del de los servicios de viaje vinculados». Entendemos que este criterio al haber quedado únicamente en el Considerando y no haber pasado al articulado, es meramente interpretativo, por lo que si el valor del servicio es algo inferior al $25 \%$ del valor de la combinación, y es evidente que es característica esencial del viaje, debiera ser considerado parte del viaje combinado.

${ }^{28}$ El Considerando Trece de la DVCSVV, concreta que tal facilitación de los servicios de viaje suele basarse en una relación comercial remunerada entre el empresario que facilita la contratación de servicios de viaje adicionales y el otro empresario, sea cual sea el método de cálculo de tal remuneración, que puede basarse, por ejemplo, en el número de clics o en el volumen de ventas. Dichas normas se aplicarían, por ejemplo, cuando, junto con la confirmación de la reserva de un primer servicio de viaje, como un vuelo o un desplazamiento en tren, el viajero recibe una invitación para reservar el alojamiento en un hotel, con un enlace al sitio web de reservas de otro prestador de servicios o intermediario.

${ }_{29}^{2}$ Panizza Fullana, señala que para los servicios asistidos de viaje (actuales «servicios de viaje vinculados»): «Se actúa sobre la base de reservas separadas». Esta 
combinado que se contrata en un único punto de venta cuando los servicios han sido seleccionados antes de que el viajero acepte pagar [3.2.b) i)]. Parece que estaremos ante un servicio de viaje vinculado cuando el viajero selecciona y paga un primer servicio, y seguidamente selecciona y paga el siguiente, y ante un viaje combinado cuando el viajero ha seleccionado la combinación de servicios, y entonces es cuando acepta pagar. Será fundamental en este caso, la prueba del pago por separado de los distintos servicios.

«b) de manera específica, la contratación con otro empresario de como mínimo un servicio de viaje adicional siempre que se celebre un contrato con ese otro empresario a más tardar 24 horas después de la confirmación de la reserva del primer servicio de viaje ${ }^{30}$ ». En este caso, entendemos que hay visitas o contactos con dos puntos de venta diferentes, y que no hay transferencia de datos del viajero entre los distintos prestadores del servicio.

\section{III.D. Exclusiones del ámbito de aplicación de la DVCSVV}

Según el art. 2.2. DVCSVV, la Directiva no se aplica a:

a) Los viajes combinados y los servicios de viaje vinculados de duración inferior a 24 horas, a menos que se incluya la pernoctación;

b) Los viajes combinados que se ofrezcan, y los servicios de viaje vinculados que se faciliten, de manera ocasional y sin ánimo de lucro únicamente a un grupo limitado de viajeros ${ }^{31}$;

misma autora advierte que: «Ambas definiciones (viajes combinados y servicio asistido de viaje) podrían tener puntos de fricción, que en cualquier caso podrían encontrar la solución en la información que debe facilitarse al viajero antes de que quede obligado por cualquier contrato $u$ oferta de servicios asistidos de viaje". PANIZZA FULLANA, A. "Nuevas tecnologías aplicadas al turismo y sus consecuencias jurídicas», en Paquetes dinámicos: problemas y soluciones jurídicas desde una perspectiva internacional. Paniza Fullana, A. (Dir.), Dykinson, 2014, págs. 25 y 26.

${ }_{30}$ «Cuando se adquiera no más de un tipo de servicio de viaje a que se refiere el punto 1, letras a), b) o c), y uno o varios de los servicios turísticos de viaje a que se refiere el punto 1, letra d), no constituirán servicios de viaje vinculados si los segundos no representan una proporción significativa del valor combinado de los servicios y no se anuncian como una característica esencial de la combinación o no constituyen por alguna otra razón una característica esencial del viaje o vacación.»

${ }^{31}$ Considerando Diecinueve DVCSVV: «Dado que la necesidad de proteger a los viajeros en los viajes de corta duración es menor, y con el fin de evitar cargas innecesarias para los empresarios, los viajes de menos de 24 horas que no incluyan alojamiento, así como los viajes combinados o los servicios de viaje vinculados que solamente se ofrecen o facilitan de manera ocasional y sin ánimo de lucro y únicamente a un grupo limitado de viajeros, deben quedar excluidos del ámbito de aplicación de la presente 
c) Los viajes combinados y los servicios de viaje vinculados contratados sobre la base de un convenio general para la organización de viajes de negocios entre un empresario y otra persona física o jurídica que actúe con fines relacionados con su actividad comercial, negocio, oficio o profesión ${ }^{32}$.

\section{SUJETOS EN EL CONTRATO DE VIAJE COMBINADO}

La DVCSVV se refiere al viajero y al empresario, como partes implicadas en el viaje combinado.

En el art. 3.6 define al viajero como: «toda persona que tiene la intención de celebrar un contrato o tiene derecho a viajar con arreglo a un contrato celebrado en el ámbito de aplicación de la presente Directiva» ${ }^{33}$. El Considerando Siete de la DVCSVV, aclara que ésta es de aplicación a los «consumidores», tal y como son definidos en la Unión Europea $^{34}$, pero también a los representantes de las pequeñas empresas o profesionales que reservan viajes relacionados con su negocio o profesión a través de los mismos canales de reserva que los consumidores y que necesitan a menudo un nivel de protección similar. Para evitar la confusión con la definición del término «consumidor» utilizado en otros actos legislativos de la Unión, procede referirse a las personas amparadas por la Directiva como «viajeros».

En el art. 3.7, la DVCSVV define al empresario como:«toda persona física o toda persona jurídica, ya sea de titularidad privada o pública, que actúe, incluso a través de otra persona que obre en su nombre o siguiendo sus instrucciones, con un propósito relacionado con su actividad comer-

Directiva. Cabe incluir entre estos últimos, por ejemplo, los viajes organizados, como mucho unas cuantas veces al año, por organizaciones benéficas, clubes deportivos o colegios para sus miembros, y no ofrecidos al público en general. Debe informarse pública y adecuadamente acerca de tal exclusión, a fin de que los empresarios y viajeros estén correctamente informados de que este tipo de viajes combinados o servicios de viaje vinculados no están incluidos en el ámbito de aplicación de la presente Directiva».

32 El Considerando Siete de la DVCSVV aclara que este último tipo de fórmulas de viaje no requiere el nivel de protección previsto para los consumidores.

${ }^{33}$ Con esta definición se abarca al potencial viajero, a efectos de información precontractual; también al contratante principal, a los beneficiarios o a los cesionarios a los que se refería el art. 2.4 de la Directiva 90/314/CEE, englobándolos en la noción de "consumidor», que llevaba a confusión con el concepto de consumidor que se utiliza en el derecho de la Unión Europea.

${ }^{34}$ Por ejemplo, la Directiva 2011/83/UE, del Parlamento Europeo y del Consejo, de 25 de octubre de 2011, sobre los derechos de los consumidores (DOUE L 304/64, 22-11-2011), en su art. 2, considera consumidor a: «Toda persona física que, en contratos regulados por la presente Directiva, actúe con un propósito ajeno a su actividad comercial, empresa, oficio o profesión». 
cial, empresa, oficio o profesión en relación con contratos regulados por la presente Directiva, tanto si actúa como organizador, minorista, empresario que facilita servicios de viaje vinculados o como prestador de servicios de viaje». De entre aquellos que tienen el carácter de empresario, concreta los conceptos de organizador y minorista. Conforme al art. 3.8 DVCSVV, se considera «organizador» no sólo al «empresario que combina y vende u ofrece viajes combinados, directamente o a través de otro empresario o junto con él», sino también al «empresario que transmite los datos del viajero a otro empresario a efectos de lo indicado en el punto 2, letra $b$ ), inciso v)». Definiéndose al «minorista» en el art. 3.9 como: «empresario distinto del organizador que vende $u$ ofrece viajes combinados compuestos por un organizador». En cuanto a si el minorista se convierte en organizador cuando vende un viaje que combina a iniciativa del propio viajero, por nuestra parte consideramos que así es, no obstante esto debería haber quedado más claro en la DVCSVV.

\section{LA INFORMACIÓN PRECONTRACTUAL AL VIAJERO EN LA DVCSVV}

En la misma línea de otras Directivas de la UE, la DVCSVV contiene un profuso listado de información que ha de suministrarse al viajero $^{35}$, aclarando el Considerando Veintisiete de la misma que: «Los requisitos de información establecidos en la presente Directiva son exhaustivos, pero deben entenderse sin perjuicio de los requisitos de información establecidos en otros actos legislativos de la Unión aplicables» ${ }^{36}$.

Como fundamento de los deberes de información precontractual se han señalado, la protección de la libertad de decidir sobre si contratar o no con pleno conocimiento de causa; permitir conocer las cualidades de la prestación en términos que permitan comparar los

${ }^{35}$ Como indica Basozabal Arrue: «Probablemente, la nota más característica de los deberes de información en los últimos años ha sido la profusión creciente de auténticos catálogos de "obligaciones de informar» a cargo del empresario frente al consumidor (tendencia que, al menos hasta hoy, encuentra su cima en los arts. 5 y ss. Directiva 2011/83 y 13 y ss, CESL)», BASOzABAL ARRUE, X. «Los deberes precontractuales de información después del DCFR, la Directiva 2011/83 y la Propuesta CESL», en La revisión de las normas europeas y nacionales de protección de los consumidores, SERGIO Cámara Lapuente, S./Arroyo i Amayuelas, E. (Coords.), Civitas, 2012, pág. 182.

${ }^{36} \mathrm{Vid}$. Pie de página 1 al que remite el Considerando Veintisiete DVCSVV, que contiene normativa europea relativa a otros deberes de información aplicables. En particular, el art. 27 DVCSVV, modifica el art. 3.3.g) de la Directiva 2011/83/UE, que considera aplicable sus arts. 6, apartado 7, 8, apartados 2 y 6, y 19, 21 y 22 de dicha Directiva, a los viajes combinados, lo que a veces supone reiterar obligaciones de información que señala la propia DVCSVV, como ocurre en relación con el precio o el idioma. 
bienes o servicios, junto con sus condiciones jurídicas y económicas favoreciéndose la competencia; facilitar la comprensión del alcance del compromiso que se adquirirá en el plano económico y jurídico ${ }^{37}$.

\section{A. Contenido y caracteres de la información precontractual al viajero en la DVCSVV}

La DVCSVV, en su art. 5.1, impone a los Estados que garanticen, que antes de que el viajero quede obligado por cualquier contrato de viaje combinado $\mathrm{u}$ oferta correspondiente ${ }^{38}$, el organizador y también el minorista, cuando el viaje combinado se venda a través de éste, proporcionen al viajero información normalizada mediante el correspondiente formulario que figura en el Anexo I, parte A o $\mathrm{B}^{39}$. Tal información se refiere principalmente a los derechos que reconoce al via-

37 Cámara Lapuente, S. "Comentario al art. 60 TRLGDCU», en CÁmara Lapuente, S. (Dir.), Comentario a las normas de protección de los consumidores, Colex, 2011, pág. 489.

38 CÁmARA LAPUENTE, hace una reflexión, en relación con el art. 60 TRLGDCU, que entendemos aplicable al tema que tratamos. Advierte que éste no establece ningún límite temporal a la «información previa al contrato», pero que ha de entenderse que ha de proporcionarse con antelación suficiente para que se cumplan los objetivos de esta obligación, lo que requerirá un examen ad casum conforme a los parámetros de la buena fe objetiva, que determinará el cumplimiento o incumplimiento de los deberes de información por razón de tiempo. CÁmARA LAPUEnTE, S. «Comentario al art. 60 TRLGDCU», ob.cit. págs. 489 a 490. Por otra parte, el art. 8.2 de la Directiva 2011/83/ UE, aplicable a los viajes combinados celebrados a distancia, se refiere al deber de suministrar información "justo antes de que el consumidor efectúe el pedido".

39 El Anexo I de la DVCVSS, en la parte A, contempla la siguiente información a facilitar para contratos de viaje combinado en los que sea posible utilizar hiperenlaces: "La combinación de servicios de viaje que se le ofrece es un viaje combinado en el sentido de la Directiva (UE) 2015/2302.

Por lo tanto, usted gozará de todos los derechos que se aplican en el marco de la UE a los viajes combinados. La(s) empresa(s) XY será(n) plenamente responsable(s) de la correcta ejecución del viaje combinado en su conjunto.

Además, como exige la legislación, la(s) empresa(s) XY está(n) cubierta(s) por una garantía para reembolsarle los pagos realizados y, si el transporte está incluido en el viaje, asegurar su repatriación en caso de que incurra(n) en insolvencia.

Más información sobre sus principales derechos con arreglo a la Directiva (UE) 2015/2302 [que se proporcionará mediante un hiperenlace]

Siguiendo el hiperenlace, el viajero recibirá la siguiente información:

Principales derechos en virtud de la Directiva (UE) 2015/2302

Los viajeros recibirán toda la información esencial sobre el viaje combinado antes de celebrar el contrato de viaje combinado.

Siempre habrá como mínimo un empresario responsable de la correcta ejecución de todos los servicios de viaje incluidos en el contrato.

Se proporcionará a los viajeros un número de teléfono de emergencia o los datos de un punto de contacto donde puedan ponerse en contacto con el organizador o el agente de viajes. 
jero la normativa aplicable, no a las características concretas del viaje a contratar, ya que se trata de una información previa para todos los viajeros, cuyo contenido queda impuesto por la norma.

Los viajeros podrán ceder el viaje combinado a otra persona, con un preaviso razonable y en su caso con sujeción al pago de gastos adicionales.

El precio del viaje combinado solo se podrá aumentar si se producen gastos específicos (por ejemplo, en los precios de combustible) y está expresamente estipulado en el contrato, y en ningún caso en los últimos veinte días anteriores al inicio del viaje combinado. Si el aumento de precio excede del $8 \%$ del precio del viaje combinado, el viajero podrá poner fin al contrato. Si el organizador se reserva el derecho de aumentar el precio, el viajero tendrá derecho a una reducción del precio si disminuyen los gastos correspondientes.

Los viajeros podrán poner fin al contrato sin pagar ninguna penalización y obtener el reembolso completo de todos los pagos realizados si se modifica significativamente alguno de los elementos esenciales del viaje combinado que no sea el precio. Si el empresario responsable del viaje combinado lo cancela antes de su inicio, los viajeros tendrán derecho al reembolso de los pagos realizados y, cuando proceda, a una indemnización.

En circunstancias excepcionales, por ejemplo en caso de que en el lugar de destino existan graves problemas de seguridad que puedan afectar al viaje combinado, los viajeros podrán poner fin al contrato antes del inicio del viaje combinado sin pagar ninguna penalización.

Además, los viajeros podrán poner fin al contrato en cualquier momento antes del inicio del viaje combinado mediante el pago de una penalización por terminación que sea adecuada y justificable.

Si, después del inicio del viaje combinado, no pueden prestarse elementos significativos de este, deberán ofrecerse al viajero fórmulas alternativas adecuadas, sin coste adicional. Los viajeros podrán poner fin al contrato sin pagar ninguna penalización en caso de no ejecución de los servicios cuando ello afecte sustancialmente a la ejecución del viaje combinado y el organizador no consiga solucionar el problema.

Los viajeros también tendrán derecho a una reducción del precio y/o a una indemnización por daños y perjuicios en caso de no ejecución o ejecución incorrecta de los servicios de viaje.

El organizador deberá proporcionar asistencia al viajero en caso de que este se encuentre en dificultades.

Si el organizador o, en algunos Estados miembros, el minorista incurre en insolvencia, se procederá a la devolución de los pagos. En caso de que el organizador o, en su caso, el minorista incurra en insolvencia después del inicio del viaje combinado y este incluya el transporte, se garantizará la repatriación de los viajeros. XY ha suscrito una garantía de protección frente a la insolvencia con YZ [la entidad garante en caso de insolvencia -por ejemplo, un fondo de garantía o una compañía de seguros-]. Si se deniegan servicios debido a la insolvencia de $X Y$, los viajeros podrán ponerse en contacto con dicha entidad o, en su caso, con la autoridad competente (datos de contacto, entre otros, nombre, dirección geográfica, correo electrónico y número de teléfono).

Directiva (UE) 2015/2302 tal como ha sido transpuesta al Derecho nacional. [HIPERENLACE]

La parte B del Anexo I, se refiere al formulario de información normalizada para contratos de viaje combinado en supuestos distintos de los contemplados en la parte A. Entendemos que se refiere a supuestos en que no haya hiperenlaces, contratos en papel o telefónicos, por ejemplo. En tal caso, se dará simultáneamente la información anteriormente descrita, si bien en el caso de contratos telefónicos, en la práctica será complejo tanto articular el suministro de toda la información, como controlar que se cumple con ello, aunque nada impide que aún siendo el contrato telefónico, la información se suministre por otro medio a distancia como el correo electrónico. 
En relación con el viaje combinado, el art. 5.1 DVCSVV contempla información más específica a suministrar al viajero, también antes de que quede obligado por cualquier contrato de viaje combinado $u$ oferta correspondiente, en caso de ser aplicable al viaje. Tal información comprende:

«a) las principales características de los servicios de viaje:

i) el destino o los destinos del viaje, el itinerario y los períodos de estancia, con sus fechas y, cuando se incluya alojamiento, el número de pernoctaciones incluidas,

ii) los medios de transporte, sus características y categorías, los puntos, fechas y horas de salida y de regreso, la duración y los lugares de las paradas intermedias y las conexiones de transporte.

Si la hora exacta está aún por determinar, el organizador y, en su caso, el minorista informarán al viajero de la hora aproximada de salida $y$ de regreso,

iii) la ubicación, principales características y, si ha lugar, categoría turística del alojamiento con arreglo a las normas del país de destino,

iv) las comidas servidas ${ }^{40}$,

v) las visitas, excursiones $u$ otros servicios incluidos en el precio total acordado del viaje combinado,

vi) en caso de que esta información no pueda deducirse del contexto, indicación de si alguno de los servicios de viaje se prestará al viajero como parte de un grupo y, en caso afirmativo, cuando sea posible, el tamaño aproximado del grupo,

vii) si el disfrute de otros servicios turísticos depende de la capacidad del viajero para comunicarse verbalmente de manera eficaz, el idioma en que se prestarán dichos servicios, $y$

viii) si el viaje o vacación es, en términos generales, apto para personas con movilidad reducida y, a petición del viajero, información precisa sobre la idoneidad del viaje o vacación en función de las necesidades del viajero;

${ }^{40}$ Actualmente, el art. 152.1.d) TRLGDCU regula el deber de informar del número de comidas que se vayan a servir y también de si las bebidas o algún tipo de ellas no estuvieran incluidas en el régimen alimenticio previsto, lo que podía haberse añadido en la Directiva, dada la frecuencia con que las bebidas quedan excluidas del precio del viaje. 
b) el nombre comercial y la dirección geográfica del organizador y, en su caso, del minorista, así como el número de teléfono y, en su caso, la dirección de correo electrónico.

c) el precio total del viaje combinado con todos los impuestos incluidos $^{41} y$, en su caso, todas las comisiones, recargos y otros costes adicionales o, si dichos costes no pueden calcularse razonablemente antes de la celebración del contrato, una indicación del tipo de costes adicionales que el viajero podrí tener que soportar;

d) las modalidades de pago, incluido cualquier importe o porcentaje del precio que deba abonarse en concepto de anticipo y los plazos para abonar el saldo, o las garantías financieras que tenga que pagar o aportar el viajero;

e) el número mínimo de personas necesario para la realización del viaje combinado y la fecha límite a que se refiere el artículo 12, apartado 3, letra a), antes del inicio del viaje combinado para la posible terminación del contrato si no se alcanza dicho número;

f) información general sobre los requisitos de pasaporte y visado, incluido el tiempo aproximado para la obtención de visados, e información sobre los trámites sanitarios para el país de destino;

g) indicación de que el viajero puede poner fin al contrato en cualquier momento antes del inicio del viaje combinado, a cambio del pago de una penalización adecuada, en su caso, de la penalización tipo aplicada por este concepto por el organizador, de conformidad con el artículo 12, apartado $1^{42}$;

${ }^{41}$ En relación con el precio, consideramos que la DVCSVV se está refiriendo al precio definitivo del viaje, con el fin de que el viajero tenga conocimiento del mismo antes de aceptar el pago, sin perjuicio de posibles modificaciones en los términos del art. 10 DVCSVV. Por ello, se trata de una obligación de información más allá de la que se exige para la comercialización del viaje, cuando se hace una «invitación a comprar», en la que es posible señalar un precio de partida; así lo admitió la STJUE (Sala segunda), de 12 de mayo de 2011, en el asunto C122/10, procedimiento entre Konsumentombudsmannen (defensor del consumidor) y Ving Sverige AB, al resolver una cuestión prejudicial sobre la interpretación de los artículos 2, letra i) y 7, apartado 4, de la Directiva 2005/29/CE del Parlamento Europeo y del Consejo, de 11 de mayo de 2005, sobre prácticas comerciales desleales de las empresas en sus relaciones con los consumidores en el mercado interior, en el caso de una Agencia que ofertaba viajes con destino a Nueva York durante un período comprendido entre septiembre y diciembre de 2008, "a partir de 7.820 coronas». Un precio de partida, sin embargo, no cumpliría la obligación de información de la DVCSVV, que obliga a garantizar que el viajero conoce el precio total de su viaje antes de contratar.

${ }^{42}$ En relación con el derecho a desistir del consumidor, se trata de una información que ya se aporta en la información normalizada de los Anexos, sin embargo tiene sentido concretarla si el organizador señala la penalización aplicable. 
h) información sobre un seguro facultativo u obligatorio que cubra los gastos de terminación del contrato por el viajero o los gastos de asistencia, incluidos los de repatriación, en caso de accidente, enfermedad o fallecimiento.

Para los contratos de viaje combinado celebrados por teléfono, el organizador y, en su caso, el minorista facilitarán al viajero la información normalizada que figura en el anexo $I$, parte $B, y$ la información indicada en las letras a) a h) del párrafo primero».

Atendiendo a las distintas posibles formas de contratar el viaje combinado, y a las particulares indicaciones que, a petición del viajero, puedan ser informadas, como las relativas a la idoneidad del viaje o vacación en función de las necesidades del viajero, incluso el precio final, según la combinación elegida, entendemos que es especialmente importante que, antes de aceptar la realización del pago, el viajero acceda a un resumen o página recapitulatoria con toda la información necesaria para garantizar que contrata el viaje con pleno conocimiento de causa.

Un caso particular es el previsto en el artículo 5.2. DVCSVV, para viajes contratados con distintos empresarios a través de procesos de reserva en línea conectados en los que el nombre del viajero, datos de pago y dirección de correo electrónico son transmitidos por el empresario con el que se celebra el primer contrato a otro $\mathrm{u}$ otros empresarios, con el o los que se celebra un contrato a más tardar 24 horas después de la confirmación de la reserva del primer servicio de viaje [art. 3.2.b).v)]; supuesto en que tanto el organizador como al empresario a los que se transmiten los datos, quedan obligados a garantizar que cada uno de ellos facilite, antes de que el viajero esté obligado por contrato o cualquier oferta correspondiente, la información indicada en el apartado 1, párrafo primero, letras a) a h), del art. 5, en la medida en que sea pertinente para los respectivos servicios de viaje que ofrezcan. Además, el organizador tendrá que facilitar también al mismo tiempo la información normalizada por medio del formulario que figura en el anexo I, parte $\mathrm{C}^{43}$.

${ }^{43}$ La Parte $\mathrm{C}$ del Anexo I obliga dar la siguiente información: «Si usted celebra un contrato con la empresa $A B$ antes de que se cumplan 24 horas de la recepción de la confirmación de la reserva enviada por la empresa $X Y$, el servicio de viaje ofrecido por $X Y Y$ AB constituirá un viaje combinado en el sentido de la Directiva (UE) 2015/2302.

Por lo tanto, usted gozará de todos los derechos que se aplican en el marco de la UE a los viajes combinados. La empresa XY será plenamente responsable de la correcta ejecución del viaje combinado en su conjunto.

Además, como exige la legislación, la empresa XY está cubierta por una garantía para reembolsarle los pagos realizados y, si el transporte está incluido en el viaje, asegu- 
Con carácter general, el art. 5.3. DVCSVV dispone que: «La información a que se hace referencia en los apartados 1 y 2 se proporcionará de manera clara, comprensible y destacada. Cuando se facilite por escrito, dicha información será legible" ${ }^{\text {44 }}$. Cuando el art. 5.3 DVCSVV se refiere a que tal información debe proporcionarse de forma «destacada», entendemos que puede hacerse de cualquier forma que no pase desapercibida al viajero, de modo que si se ofrece verbalmente debería hacerse referencia a que se está suministrando información importante para la contratación. Respecto al carácter «legible» de la información escrita, en nuestro derecho interno puede interpretarse tomando como referencia el art. 80 del TRLGDCU ${ }^{45}$, aún cuando éste se aplica a las cláusulas no negociadas individualmente de los contratos con consumidores y usuarios, requiriendo que las mismas sean accesibles y legibles, disponiendo que: "En ningún caso se entenderá cumplido este requisito si el tamaño de la letra del contrato fuese inferior al milímetro y medio o el insuficiente contraste con el fondo hiciese dificultosa la lectura». En el caso de información suministrada on line consideramos que la configuración inicial del mensaje informativo debe respetar el carácter legible del mismo, por mucho que el viajero pueda ampliar el tamaño de la letra en su dispositivo.

\section{V.B. Carácter vinculante de la información precontractual en los viajes combinados}

V. B.1. Regulación y antecedentes del carácter vinculante de la información precontractual en los viajes combinados

El artículo 6 de la DVCSVV bajo la rúbrica «Carácter vinculante de la información precontractual y celebración del contrato de viaje combinado» ${ }^{46}$, dispone:

rar su repatriación en caso de que incurra en insolvencia. Más información sobre derechos principales con arreglo a la Directiva (UE) 2015/2302 [que se proporcionará mediante un hiperenlace] Debiéndose facilitar a través del hiperenlace la misma información que se señala en la parte A.

${ }^{44} \mathrm{El}$ art. 60 del TRLGDCU, exige que la información precontractual que se facilite al consumidor sea clara y comprensible. Y el art. 152.1 TRLGDCU para los viajes combinados en concreto, exige que la información sea: «clara, comprensible y preci$s a »$. Como vemos, en la transposición de la DVCSVV, habrá que añadir que se haga de forma «destacada».

${ }^{45}$ Letra b) del número 1 del artículo 80 redactada por el apartado 25 del artículo único de la Ley 3/2014, de 27 de marzo, por la que se modifica el TRLGDCU.

${ }^{46} \mathrm{La}$ propia rúbrica del art. 5 pone de manifiesto la relación entre la información precontractual y el contrato. 
«1. Los Estados miembros garantizarán que la información facilitada al viajero con arreglo al artículo 5, apartado 1, párrafo primero, letras a), c), d), e) y g), forme parte integrante del contrato de viaje combinado y no se modifique salvo que las partes contratantes acuerden expresamente lo contrario. El organizador y, en su caso, el minorista, comunicarán de forma clara, comprensible y destacada al viajero, antes de la celebración del contrato de viaje combinado, todos los cambios de la información precontractual.

2. Si el organizador, y en su caso el minorista, no cumple con los requisitos de información sobre comisiones, recargos $u$ otros costes adicionales contemplados en el artículo 5, apartado 1, párrafo primero, letra c), antes de la celebración del contrato de viaje combinado, el viajero no tendrá que soportar dichas comisiones, recargos $u$ otros costes».

Estamos ante un supuesto de integración de la información precontractual en el contrato, tratándose de proteger la confianza que tal información genera en el viajero ${ }^{47}$. Al dotar a la información precontractual de carácter vinculante, se protege la expectativa legítima del viajero, que habrá confiado a la hora de seleccionar su viaje en el contenido de tal información, conforme a la cual ha podido adoptar múltiples decisiones, como contratar ese viaje en particular y no otro, hacerlo en unas determinadas fechas, lo que conlleva muchas veces organización familiar y laboral, adquirir bienes necesarios para llevarlo a cabo...Incluso a veces su planificación es indispensable para acudir a una reunión importante o evento familiar o social. Por ello, es trascendental que el organizador y el minorista respeten en el contrato y durante su ejecución, la información precontractual que ofrecieron al viajero acerca del viaje $e^{48}$.

No obstante, la DVCSVV prevé la posibilidad de que tal información precontractual pueda ser modificada, señalando las necesarias

47 El profesor Lasarte, ya señalaba, en relación con normativa anterior, que esta regulación: «...es sencillamente una concreción de lo establecido en el art. 8.1. de la Ley de Defensa de los Consumidores y Usuarios». LASARTe Álvarez, C. "Protección al consumidor y carácter vinculante del folleto informativo en los «viajes combinados». En torno a la Ley 21/1995, de 6 de julio, y la jurisprudencia precedente»), Revista Crítica de Derecho Inmobiliario, n. ${ }^{\circ}$ 643, 1997, pág. 2.203; En el mismo sentido PASTOR SEMPERE, M. C. «El viaje combinado en el RDLG 1/2007 (Texto refundido Ley General de Consumidores) y Leyes complementarias», Cuadernos de Turismo, n. ${ }^{\circ}$ 25, 2010, pág. 111.

${ }^{48}$ La SAP de Badajoz, de 6 de septiembre de 1995 (SAP 1727/1995), condenó a la agencia a indemnizar por daño moral, al considerar que las características de un viaje a China que figuraban en los folletos publicitarios son plenamente exigibles por los clientes en virtud de lo dispuesto en el art. 8 de la LGDCU, y no cumplirse, en parte, las mismas. En particular, no se puso a disposición de los viajeros un guía acompañante de habla hispana durante todo el recorrido, al que se hacía referencia en el folleto publicitario. 
garantías para que los cambios en la misma no sean sorpresivos para el viajero. Como indica la Comunicación de la Comisión «Adaptar la normativa europea sobre viajes combinados a la era digital»: "... los circuitos y vacaciones combinados son complejas combinaciones de servicios de viajes, en los que a menudo están implicados varios proveedores de servicios», además, al suponer un desplazamiento, su configuración puede verse influenciada por muy distintas circunstancias, por lo que no es extraño que se haya previsto la posibilidad de modificación de los contenidos inicialmente informados al viajero.

Como antecedente inmediato al carácter vinculante de la información precontractual en los viajes combinados, el art. 3 de la derogada Directiva de viajes combinados ${ }^{49}$, señalaba que: «La información contenida en el folleto será vinculante para el organizador o el detallista, a menos que:

- los cambios en dicha información se hayan comunicado claramente al consumidor antes de la celebración del contrato; el folleto deberá mencionarlo expresamente;

- se produzcan posteriormente modificaciones, previo acuerdo entre las partes contratantes.

Esta previsión se recoge en el art.153 TRLGDCU, con la diferencia de que no se refiere al «folleto» sino al "programa-oferta», que deja claro que la información es vinculante para el organizador y también para el detallista, y que exige que los cambios en la información deberían comunicarse por escrito, lo que otorga mayor garantía al viajero.

Por su parte, la Propuesta de Directiva relativa a los viajes combinados y los servicios asistidos de viaje, antecedente inmediato de la DVCSVV, disponía en su art. 5 que: «1. Los Estados miembros garantizarán que el organizador no podrá modificar la información facilitada al viajero con arreglo al artículo 4, letras a), c), d), e) y g), salvo que el organizador se reserve el derecho de introducir cambios en esa información y comunique dichos cambios al viajero de forma clara y visible antes de la celebración del contrato».

Las diferencias fundamentales que observamos entre el art. 6 DVCSVV y la Directiva derogada, e incluso la Propuesta de Directiva antecedente de la actual, son las siguientes:

49 Vid. comentario crítico a este artículo en CAMACHO PEREIRA, C. «El alcance vinculante del programa-oferta en los viajes combinados y la responsabilidad del organizador o detallista ante su incumplimiento", en Turismo y Desarrollo Económico: IV Jornadas de Investigación en Turismo, coord. por JimÉnez CABALLERO, J. L/DE Fuentes RuIZ, P., 2011, págs. 475-498. 
- Queda claro en el art. 6 DVCSVV que la responsabilidad en el suministro de la información precontractual es tanto del organizador como del minorista.

- El art. 6 DVCSVV ya no hace referencia a que la información se encuentre contenida en el «folleto», ya que la información precontractual puede constar en otro soporte, si atendemos a la evolución de las nuevas tecnologías que además permiten actualizaciones con facilidad ${ }^{50}$.

- Consideramos, que el art. 6 DVCSVV no legitima al organizador a realizar modificaciones unilaterales de la información precontractual, ni siquiera en el supuesto de que se hubiera reservado tal derecho. Sin embargo, el Considerando Veintiséis de la DVCSVV, que más parece ser la explicación de la normativa anterior o de la Propuesta de Directiva, sí se refiere a tal posibilidad, al señalar que: «La información clave, por ejemplo, sobre las principales características de los servicios de viaje o los precios, proporcionada en los anuncios, en el sitio web del organizador o en folletos como parte de la información precontractual, debe ser vinculante, salvo si el organizador se reserva el derecho de modificar esos elementos y las modificaciones son comunicadas de forma clara, comprensible y destacada al viajero antes de la celebración del contrato de viaje combinado». Existe por tanto incongruencia entre este considerando y el artículo 6 de la Directiva, debiéndose estar a la literalidad de este último.

- La Directiva derogada se refería a dos supuestos diferentes en que se podía alterar la información precontractual, el primero, que habiendo previsto esa información la posibilidad de cambios en la misma, existieran estos, y se comunicaran al consumidor antes de celebrar el contrato, por lo que tales cambios podían hacerse de forma unilateral por el empresario; el segundo, que por acuerdo de las partes, "posteriormente» hubiera modificaciones. Parece que este segundo supuesto, se refería a modificaciones una vez que se hubiera contratado ${ }^{51}$. En cambio, el art. 6 DVCSVV, conforme

${ }^{50}$ Considerando veintiséis DVCSVV. Según la Comunicación de la Comisión "Adaptar la normativa europea sobre viajes combinados a la era digital», las normas actuales han obligado a las empresas a reeditar innecesariamente su material publicitario, incurriendo así en costes indebidos de alrededor de 390 millones de euros al año.

51 De La Haza Díaz considera este apartado un «precepto inútil»: «... en primer lugar, porque si ya existe contrato, que ha de ser escrito,... no hay más posibilidad de 
a la interpretación que mantenemos, supone que para que la información precontractual pueda considerarse modificada es preciso acuerdo expreso de las partes contratantes, y que, previamente, antes de la celebración del contrato, el organizador y, en su caso, el minorista, hubieran comunicado de forma clara, comprensible y destacada al viajero, todos los cambios de la información precontractual. Es decir, se trataría de requisitos cumulativos, de manera que los cambios en la información precontractual únicamente son oponibles al viajero si han sido previamente informados antes de celebrarse el contrato, y si además, han sido objeto de acuerdo expreso entre los contratantes. No creemos que la posibilidad prevista de que la información facilitada al viajero integre el contrato y no se modifique salvo que «las partes contratantes acuerden expresamente lo contrario", pueda entenderse referida a un acuerdo genérico de exclusión de la integración de la información precontractual en el contrato; admitir tal interpretación supondría mermar los derechos y garantías del viajero.

- Las modificaciones de la información precontractual han de comunicarse al viajero de forma clara, comprensible y destacada, antes de acordarlas expresamente, mientras que la anterior regulación se refería a que se comunicasen claramente. Entendemos que el carácter destacado de las modificaciones, exigirá que sean visibles, legibles, y que el consumidor pueda reparar no sólo en su contenido, sino además en que se está modificando lo anteriormente informado.

- Por último, el art. 6 DVCSVV, introduce un nuevo apartado 2, para el caso de que el organizador, y en su caso, el minorista, no cumplan con los requisitos de información sobre comisiones, recargos $\mathrm{u}$ otros costes adicionales contemplados en el artículo 5, apartado 1, párrafo primero, letra c), antes de la celebración del contrato de viaje combinado; en ese caso el viajero no tendrá que soportar dichas comisiones, recargos u otros costes. Se trata de una sanción civil por omisión de información precontractual que beneficia al viajero que no espera soportar tales costes al no haber sido informado de ello, y que incentiva el cumplimiento de tal información por

modificarlo que mediante un nuevo acuerdo, también escrito; se trata de una convención novatoria o modificativa del acuerdo anterior...». DE LA HAZA DÍAZ, P. "La oferta publicitaria de los viajes combinados», Estudios sobre consumo, n. ${ }^{\circ} 47,1998$, INC, pág. 18. 
el empresario, ya que si no informa debidamente, no podrá reclamar el pago de comisiones, recargos o costes adicionales al viajero ${ }^{52}$.

Como novedad respecto a la normativa anterior, la DVCSVV, en su art. 8, se refiere a la carga de la prueba en relación con el cumplimiento de los requisitos de información, señalando expresamente que recaerá en el empresario.

\section{B.2. La integración de la información precontractual en el contrato de viajes combinados.}

Como hemos visto, el dotar de carácter vinculante a la información precontractual no es una novedad, ni en el ámbito europeo, ni en nuestra normativa interna. En el ámbito europeo ${ }^{53}$ ya se había contemplado con ocasión de los «Principios de Derecho Europeo de los Contratos» (PECL) y del Proyecto de Marco Común de Referencia, "Principios, definiciones y reglas modelo de Derecho Privado Europeo» Draft Common Frame of Reference (DCFR) ${ }^{54}$, que planteó como uno de los aspectos que lo inspiran, la protección de la confianza y de las expectativas razonables del consumidor. En concreto, el art. II-9:102 de estos principios se refiere a "Ciertas declaraciones precontractuales consideradas como términos del contrato», y en su apartado 2 dispone que las declaraciones realizadas por el empresario a los consumidores antes de la conclusión del contrato, acerca de las características con-

${ }^{52}$ Esta previsión sigue la línea marcada por el art. 6.6 de la Directiva 2011/83/UE, del Parlamento Europeo y del Consejo, de 25 de octubre de 2011, sobre los derechos de los consumidores (DOUE L 22.11.2011).

${ }^{53}$ Para un estudio más amplio puede consultarse, entre otros: CAMACHO PEREIRA, C. «Comparativa de la regulación de la integración de la publicidad en el contrato con consumidores, en el TRLGDCU y en la Propuesta de Reglamento del Parlamento Europeo y del Consejo, relativo a una normativa común de compraventa europea», InDret, 2012, vol. 4, págs. 1-28; «La protección del consumidor frente al mensaje publicitario. Integración de la publicidad en el contrato», Thomson Reuters Aranzadi, Navarra, 2012, págs. 253-260. CÁmara Lapuente, S./Arroyo i Amayuelas, E. (Coords). La revisión de las normas europeas y nacionales de protección de los consumidores: más allá de la Directiva sobre derechos de los consumidores y del Instrumento Opcional sobre un derecho europeo de la compraventa, de octubre de 2011. Civitas, 2012. INFANTE RuIZ, F. J., «The Integration of Advertising Statements into the Content of the Contract», en European Perspectives on the Common European Sales Law, Plaza PenEdÉs, J./MarTíNEZ Velencoso, L. M. (Eds.). Springer, 2015, págs. 67-92; Schulze, R.: «Deberes precontractuales y conclusión del contrato en el Derecho Contractual Europeo», Anuario de Derecho Civil, vol. 59, n. ${ }^{\circ} 1,2006$, págs. 29 a 58.

${ }^{54}$ Von Bar, C./Clive, E./Schulte Nölke, H., (Eds.), Principles, Definitions and Model Rules of European Private Law, Draft Common Frame of Reference (DCFR), European law publishers GmbH, Munich, Sellier, 2009. February 
cretas de lo que va a suministrar, son consideradas como término del contrato, a menos que: a) La otra parte conociera al tiempo de la formalización del contrato, o podía esperarse razonablemente que hubiera conocido, que la declaración era incorrecta o de alguna otra manera no pudo confiar en tales términos o b) La decisión de la otra parte para concluir el contrato no haya estado influenciada por la declaración. Por otra parte, en el art. II-3:109 (2) de estos Principios, se prevé el supuesto de que el contrato se haya llegado efectivamente a celebrar y el profesional no haya cumplido algunos de los deberes de información que le son exigidos en su contratación con los consumidores. En esta situación se dispone que el profesional queda obligado por el contrato a todo lo que la otra parte hubiera podido razonablemente esperar como consecuencia de la ausencia o defecto de la información. De este modo, el contenido contractual queda integrado, no sólo por el estricto acuerdo de las partes, sino también por las legítimas expectativas de la parte que ha visto violados sus derechos de información ${ }^{55}$.

Por su parte, la Propuesta de Reglamento del Parlamento Europeo y del Consejo relativa a una normativa común de compraventa europea (CESL), aprobada el 11 de octubre de $2011^{56}$, en el Anexo I, art. 69, bajo la rúbrica "Cláusulas contractuales derivadas de determinadas declaraciones precontractuales» reconoce la integración de determinadas declaraciones precontractuales del comerciante en el contrato que celebra con una Pyme o con el consumidor, salvo que «la otra parte conociera o pudiera esperarse que conociera, en el momento de la celebración del contrato, que la declaración no era exacta o que no se le podía dar crédito como cláusula del contrato; o(b) la declaración no pudiera haber influido en la decisión de la otra parte de celebrar el contrato» ${ }^{57}$. Poniendo en relación los arts. 69, 99.3 y 100 de esta Propuesta, puede advertirse que lo declarado públicamente no puede ser reclamado por el consumidor si en el momento de contratar conocía que tales decla-

55 García Rubio, M. P. y Otero Crespo, M., «La responsabilidad precontractual en el Derecho contractual europeo», InDret, n. ${ }^{\circ}$ 2, 2010, 'www.indret.com', pág. 14.

${ }^{56} \operatorname{COM}(2011,635$ final), de 11.10.2011

57 La Resolución legislativa del Parlamento Europeo, 26.2.2014, sobre la Propuesta de Reglamento del Parlamento Europeo y del Consejo relativa a una normativa común de compraventa europea, en la enmienda n. ${ }^{\circ} 140$ excluye de la consideración de cláusula del contrato la declaración pública que se hubiese «corregido en el momento de celebrar el contrato». Entendemos que la referencia al momento mismo de la celebración del contrato no debería admitirse, para permitir reflexionar al cliente debería indicarse, al menos, que la información estuviera corregida con antelación suficiente a la celebración del contrato. 
raciones acerca de prestaciones o cualidades de los bienes eran inexactas o increíbles, y aunque se viera perjudicado, "si en el momento de la celebración del contrato, el consumidor conocía las condiciones específicas de los bienes o los contenidos digitales y los aceptó como conformes con el contrato en el momento de su celebración».

Por tanto, en el ámbito europeo, existe una tendencia a dotar de eficacia negocial a las declaraciones precontractuales emitidas por el empresario, teniendo por fundamento la protección de las legítimas expectativas que generan en el destinatario. Con este mismo fundamento, entre otras, la Directiva sobre determinados aspectos de la venta y garantías de los bienes de consumo ${ }^{58}$ considera que para que un bien sea conforme con el contrato debe ser acorde con las declaraciones públicas sobre las características concretas de los bienes hechas por el vendedor, el productor o su representante, en particular, en la publicidad o el etiquetado; si bien el vendedor no quedará obligado por las declaraciones públicas si demuestra que dicha declaración había sido corregida en el momento de la celebración del contrato ${ }^{59}$; con mayores garantías, la Directiva 2008/122/CE, del Parlamento Europeo y del Consejo, de 14 de enero de 2009, relativa a la protección de los consumidores con respecto a determinados aspectos de los contratos de aprovechamiento por turno de bienes de uso turístico, de adquisición de productos vacacionales de larga duración, de reventa y de intercambio ${ }^{60}$, sólo permite que la información precontractual vinculante, se altere por acuerdo expreso de las partes o por fuerza mayor, previa comunicación al consumidor de los cambios en papel o en cualquier otro soporte duradero fácilmente accesible, antes de que se celebre el contrato ${ }^{61}$; el art. 6.5 de la Directiva 2011/83/UE, del Parlamento Europeo y del Consejo, de 25 de octubre de 2011, sobre los derechos de los consumidores, también considera que la información precontractual formará parte integrante del contrato a distan-

58 Directiva 1999/44/CE del Parlamento Europeo y del Consejo, de 25 de mayo de 1999, sobre determinados aspectos de la venta y las garantías de los bienes de consumo; DO L 171, 7.7.1999 (art. 2), modificada por la Directiva 2011/83/UE del Parlamento Europeo y del Consejo, de 25 de octubre de 2011 sobre los derechos de los consumidores, DO L 304 de 22.11.2011.

59 En este sentido art. 116.1.d) TRLGDCU.

${ }^{60}$ Directiva 2008/122/CE, del Parlamento Europeo y del Consejo, de 14 de enero de 2009, relativa a la protección de los consumidores con respecto a determinados aspectos de los contratos de aprovechamiento por turno de bienes de uso turístico, de adquisición de productos vacacionales de larga duración, de reventa y de intercambio DO L 33/10, de 3.2.2009 (art. 5.2)

${ }^{61}$ En este sentido el art. 11.2 de la Ley 4/2012, de 6 de julio, de contratos de aprovechamiento por turno de bienes de uso turístico, de adquisición de productos vacacionales de larga duración, de reventa y de intercambio y normas tributarias. 
cia o celebrado fuera del establecimiento y no se alterará a menos que las partes dispongan expresamente lo contrario ${ }^{62}$. En la línea de las dos últimas Directivas referidas estaría la DVCSVV.

En nuestro derecho interno, la integración de las declaraciones precontractuales en el contrato cuenta como antecedente remoto con el art. 1.258 CC y la jurisprudencia del Tribunal Supremo ${ }^{63}$, y más inmediato con el ya derogado art. 8 de la Ley 26/1984, de 19 de julio, General para la Defensa de los Consumidores y Usuarios ${ }^{64}$. Actualmente el art. 61 TRLGDCU regula "La integración de la oferta, promoción y publicidad en el contrato»; conforme a sus apartados 2 y 3: «2. El contenido de la oferta, promoción o publicidad,... serán exigibles por los consumidores y usuarios, aun cuando no figuren expresamente en el contrato celebrado o en el documento o comprobante recibido y deberán tenerse en cuenta en la determinación del principio de conformidad con el contrato. 3. No obstante lo dispuesto en el apartado anterior, si el contrato celebrado contuviese cláusulas más beneficiosas, éstas prevalecerán sobre el contenido de la oferta, promoción o publicidad». Por su parte, el art. 65, relativo a la "Integración del contrato», ensalza a principio rector de la contratación con consumidores el de la buena fe objetiva disponiendo que: "Los contratos con los consumidores se integrarán, en beneficio del consumidor, conforme al principio de buena fe objetiva, también en los supuestos de omisión de información precontractual relevante».

Esta cuestión no es desconocida para nuestros Tribunales. El Tribunal Supremo, en los supuestos en que se resuelven casos de laguna contractual, admite claramente la integración de lo declarado públicamente en el contrato, colmándose tal laguna con los contenidos de lo declarado públicamente ${ }^{65}$. En cambio, en los supuestos de discrepancia entre lo declarado públicamente y lo expresamente pactado por las partes, se inclina por dar mayor relevancia a lo pactado, ha-

62 Art. 97.5 TRLGDCU.

63 STS de 14 de junio de 1976 (RJ 1976 2753); STS de 27 de enero de 1977 (RJ 1977121 ), comentada ampliamente por el profesor LASARTE ÁlvAREZ, C: «Sobre la integración del contrato: la buena fe en la contratación. En torno a la sentencia del T. S. de 27 de enero de 1977», Revista de Derecho Privado, n. ${ }^{\circ}$ 64, mes 1, 1980, págs. 51 a 78. STS de 9 de febrero de 1981 (RJ 1981\533). También en este sentido la STS de 7 de noviembre de 1988 (RJ 1988\8419): "... lo que sirvió de público y general ofrecimiento indudablemente, y en tanto no se excluya expresamente, es comprendido con base en esa oferta».

${ }^{64}$ BOE núm. 176, de 24.7.1984

65 Vid. entre otras, STS 21-7-1993 (RJ 1993,6176); SAP Sevilla (24-7-2003 (JUR 2003,209335); SAP Córdoba, 17-7-1998 (AC 1998, 1361); SAP Cantabria, 14-3-1996 (AC 1996,548). 
ciendo prevalecer el principio de autonomía de la voluntad, admitiendo la renuncia a lo declarado públicamente aunque sea más favorable al consumidor, si esta tiene lugar en el contrato de forma expresa y concreta $^{66}$. En cambio en el ámbito de las Audiencias, en algún supuesto el consumidor contrató la prestación a sabiendas de que no era coincidente con lo publicitado, ante la posible pérdida de cantidades entregadas, $\mathrm{u}$ otros perjuicios personales, y se aprecia la contratación por resignación, o con una voluntad presionada, estimándose la existencia de incumplimiento contractual ${ }^{67}$ en relación con la información previa, con condena a la empresa incluso a indemnizar daños morales en algún caso ${ }^{68}$.

En cuanto a la doctrina, coincide en reconocer el carácter vinculante de las declaraciones públicas del empresario ${ }^{69}$, si bien existen

${ }^{66}$ STS 8.11.1996 (RJ 1996, 8260), STS 15.3.2010 (RJ 2010, 2347).

67 SAP de Murcia, 23.1.2001 (AC 2001,728).

68 SAP Segovia, 13.12.1993 (AC 1993, 2405).

69 Este tema ha sido estudiado ampliamente entre otros, por CABALLERo LozANo, J. M. «Eficacia contractual de la publicidad comercial en la jurisprudencia», Actualidad Civil, n. ${ }^{\circ}$ 13, 1996, págs. 293- 305. CAMACHO Pereira, C. La protección del consumidor... ob. cit., págs. 222-364. CÁmara Lapuente, S. "Comentario al art.61 TRLGDCU»/«Comentario al art. 65 TRLGDCU», en CÁmARA LAPUENTE, S. (Dir.) Comentario a las normas de protección de los consumidores, COLEX, Madrid, 2011, págs. 510-537/579-605. CoRRAL GARCía, E.: «La protección de los consumidores a través de la eficacia contractual de la publicidad», Actualidad Civil, n. ${ }^{\circ} 38$, octubre, 2000, págs. 1.399-1.416. Díaz Gómez, M. A. "Ámbito subjetivo y objetivo de la integración publicitaria prevista en el artículo 61 del texto refundido de la Ley General para la Defensa de los consumidores y usuarios", Revista de Derecho de la Competencia y Distribución, n. ${ }^{\circ} 2$, 2008, págs. 65- 69. FonT GALÁN, J. I. «Publicidad comercial y contrato con consumidores. Conexiones funcionales y normativas: sustantivación obligacional e integración contractual de las ofertas promocionales y publicitarias», en ReBollo PUiG, M./IzQuierdo Carrasco, M. (Dirs.), La Defensa de los consumidores y usuarios. Comentario sistemático del Texto Refundido aprobado por el Real Decreto Legislativo 1/2007, 1. ${ }^{\text {a }}$ ed., Iustel, Madrid, págs. 1.132-1.186. GARCÍA VICENTE, J. R.: «Comentario al artículo 61 TRLGDCU»/ "Comentario al artículo 65 TRLGDCU», en Comentario del Texto Refundido de la Ley general para la defensa de los Consumidores y usuarios y otras leyes complementarias (Real Decreto Legislativo 1/2007). BERCOVITZ RodRíGuEZCANO, R. (Coord.), ed. Aranzadi, Navarra, 2009, págs. 779-793/819-825. InFANTE RuIZ, F. J.: «La integración del contrato con el contenido de la publicidad. Comentario a la STS de 23 de mayo 2003 (RJ 2003, 5215)», Revista de Derecho Patrimonial, n. ${ }^{\circ} 12$, 2004, págs. 195- 212; "The Integration of Advertising....», ob. cit.; «La promoción...», $o b$. cit. págs. 218-269. LASARTE ÁlVAREZ, C. «Sobre la integración del contrato...», ob. cit. págs. 51 a 78. MarTín García, M. L.: La publicidad, su incidencia en la contratación, ed. Dykinson, Madrid, 2002. Miranda Serrano, L. M y Paniagua Zurera, M., «La protección de los consumidores y usuarios en la fase previa a la contratación: la tutela de la libertad negocial», en Miranda SERrano, L. M y Pagador López, J (Coords.), Derecho (privado) de los consumidores, 1. a ed., Marcial Pons, Madrid, 2012, págs. 63-98. Morales Moreno, A. M.: «Información publicitaria y protección del consumidor: Reflexiones sobre el artículo 8 LGCU», en Homenaje a Juan Vallet de Goytisolo, Junta de Decanos de los Colegios Notariales de España, Consejo General del 
distintos planteamientos sobre el alcance de la exigibilidad de las mismas cuando lo finalmente reflejado en el contrato discrepa de su contenido, en particular, cuando es menos favorable para el destinatario que lo manifestado públicamente ${ }^{70}$. Un sector de la doctrina defiende que, al integrarse tales declaraciones en el contrato, el consumidor debería poder exigir lo que le sea más favorable entre lo declarado públicamente o lo contratado ${ }^{71}$. Algunos autores matizan que la forma de evitar posibles abusos por el consumidor, sería acudir a la «teoría general de los limites intrínsecos del derecho subjetivo, de tal manera que la doctrina de los propios actos, la buena fe en el ejercicio de los derechos (art.7.1 CC) y el abuso del derecho (art.7.2 CC) podrán constituir instrumentos valiosos en manos del juez para evitar los exce-

Notariado, vol. 8, Madrid 1992, págs. 667-693. Pasouau Liaño, M.: «Comentario al artículo 8 párrafos $1 .^{\circ}$ y $2 .^{\circ}$ LGDCU», en Comentarios a la Ley General para la Defensa de los Consumidores y Usuarios. Bercovitz Rodríguez-Cano, R./Salas Hernández, J. (Coords), ed. Civitas, Madrid, 1989, págs. 142-178 y «La protección de las legítimas expectativas del consumidor y la exigibilidad de las promesas publicitarias: una propuesta de superación del artículo 8 de la Ley de Consumidores y Usuarios», Revista de Autocontrol, n. ${ }^{\circ}$ 56, págs. 24- 27. PINO ABAD, M. «Comentarios a los artículos 61 y 65. La relevancia negocial de la publicidad comercial: integración publicitaria del contrato celebrado con consumidores", en La Defensa de los consumidores y usuarios. Comentario sistemático del Texto Refundido aprobado por el Real Decreto Legislativo 1/2007. Rebollo Puig, M./Izouierdo Carrasco, M. (Dirs.), ed. Iustel, Madrid, 2011. págs. 1.106 a 1.131. REYES LÓPEZ, M. J. El carácter vinculante de la oferta y de la publicidad en el art. 8 LGDCU, Estudios sobre consumo, N. ${ }^{\circ}$ 43, 1997, págs. 63-86.

70 Pasquau Liaño, M., "Comentario al art. 8...», ob. cit. pág. 164, con relación al antiguo art. 8 TRLGDCU, señala con acierto que: «... el problema fundamental de esta norma no es entender lo que quiere decir, sino ponerle límites».

${ }^{71}$ Corral García, E. "La protección de los consumidores a través de...», ob.cit. pág. 1407; FonT GALÁN, J. I., «La integración publicitaria del contrato: un instrumento de Derecho Privado contra la publicidad engañosa", Cuadernos de Derecho y Comercio, núm. 4, 1988, págs. 35-36; Para Font: «el contenido negocial u obligacional de tales declaraciones públicas de ofertas publicitarias o promocionales resulta indisponible o irrevocable para el comerciante contratante responsable de las mismas», FonT GALÁN, J. I. «Publicidad comercial y contrato con consumidores...», ob.cit. pág. 1.176. Para Infante: «... el fundamento se cifra no en el riesgo de que la publicidad cree una situación de apariencia, sino en el mero dato de que exista un desfase entre el contenido de la publicidad y el del contrato, estableciéndose una imputación objetiva directa (normativa) del resultado, sin recurso a ningún otro criterio». INFANTE RUIZ, F. J.: «La integración del contrato con el contenido de la publicidad..., ob. cit, pág. 208:«La promoción...», ob.cit. pág. 252. LASARTE ÁlvAREZ, C., "La protección del consumidor como principio general del derecho», Estudios sobre Consumo, núm. 73, Madrid, 2005, pág. 65. El profesor Lasarte, en relación con la regla de integración del contrato contenida en el art. $1258 \mathrm{Cc}$, señala con claridad. que se trata de una norma de «ius cogens», "aplicable con independencia de la voluntad de las partes, no pudiendo ser excluido en términos generales por la regla autónoma», LASARTE ÁLVAREZ, C. "Sobre la integración...», ob. cit., pág. 73. LóPEz SÁNCHEZ, M. A. «Publicidad comercial, contratación estandarizada y protección del consumidor», Estudios sobre consumo, núm. 16, INC, Madrid, 1989, pág.73. Miranda Serrano, L. M., ob. cit, pág. 72. 
sos a que pudiera dar lugar esta norma»72; Por otra parte, en la línea de los trabajos y Directivas de la UE, hay autores que fundamentan la relevancia contractual de la información declarada públicamente en las «expectativas razonables» generadas en el consumidor respecto del producto o servicio que adquirió. De esta forma, lo declarado públicamente será o no vinculante según que, dadas las circunstancias, un contratante medio pueda pensar razonablemente que forma parte del

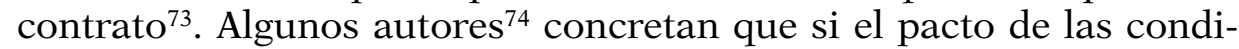
ciones discordantes con la declaración previa ha tenido lugar por negociación individual, el consumidor no puede exigir los contenidos de la misma, debiendo estar a lo pactado, pero si se altera la información previa por pacto en condiciones generales de la contratación sí podría hacerlo, presumiendo que cuando el consumidor se adhiere a un condicionado general previamente redactado por la empresa, su voluntad se encuentra mermada, de modo que la suscripción del mismo no destruye la confianza en las declaraciones previas ${ }^{75}$.

72 CÁmara Lapuente, S. "Comentario al art. 61 TRLGDCU», ob.cit. pág. 537. PasQUAu Liaño, M. "Comentario al artículo 8...», ob. cit., págs. 170-171. MiRANDa SERRANo, L. M y Paniagua ZuRera, M., "La protección de los consumidores y usuarios...», ob. cit., pág. 91 .

${ }^{73}$ Según Cámara Lapuente: «... la protección de las legítimas expectativas basadas en la confianza generada con las declaraciones publicitarias es el fin último tutelado por el artículo 61 TRLGDCU, de acuerdo con las exigencias de la buena fe objetiva en el ejercicio de los derechos subjetivos, establecidas en los arts. 7.1 y 1258 Cc y 65 TR...». CÁmara LaPUente, S. «Comentario al art. 61 TRLGDCU», ob. cit., pág. 517; Morales MoRENO. A. M, «Declaraciones públicas y vinculación contractual. Reflexiones sobre una Propuesta de Directiva», Anuario de Derecho Civil, Vol. 52. ', núm. 1, 1999, pág. 275; PASQUAU LiAÑo, M., «La protección de las 'legítimas expectativas' del consumidor y la exigibilidad de las promesas publicitarias: una propuesta de superación del artículo 8 de la Ley General de Consumidores y Usuarios», núm. 56, (www.autocontrol. es), 2001, págs. 27 y 28. Según este autor, la fuerza vinculante de las declaraciones públicas «entra en juego cuando no pueda calificarse como infundada, ilegítima o irrazonable, es decir, contraria a la buena fe, la pretensión del consumidor de exigir su cumplimiento a pesar de la información en contra dada por el vendedor en el momento de la contratación».

74 CÁmara Lapuente, S. "Comentario al art. 61 TRLGDCU», ob. cit., pág. 523; Díez-Picazo y Ponce de León, L., Fundamentos de Derecho Civil Patrimonial, I, Civitas, Madrid, 1996, pág. 328; GARcía ViCEnTE, J. R., "Comentario al artículo 61...», ob.cit., pág. 786, INFANTE Ruíz, F. J., «La integración del contrato con el contenido de la publicidad...», ob. cit., pág. 206.

75 El contrato de viaje combinado suele considerarse contrato de adhesión, aún cuando alguna o algunas cláusulas puedan haberse negociado individualmente (art. 1.2 Ley 7/1998, de 13 de abril, sobre condiciones generales de la contratación (LCGC). BOE núm. 89, de 14.04.1998). HERNÁNDEZ DíAZ-AMBRONA, considera que no está tan claro cuando se permiten modificaciones posteriores en el programa-oferta por acuerdo previo de las partes. HERnández DíAZ-AmBronA, M., "Viajes combinados», en Derecho civil de la Unión Europea, Díaz-Ambrona Bardají, M. D, Hernández DíazAmbrona, M, Pous de la Flor, M. P., Tejedor Muñoz, L., Colex, 2012. 
Una vez expuestos los antecedentes del reconocimiento de la integración de las declaraciones previas en el contrato, y los distintos planteamientos en cuanto a sus límites, nos centraremos en el alcance vinculante de la información precontractual en la DVCSVV. En la transposición a nuestro derecho interno de esta cuestión, hay que tener en cuenta, que no cabe otorgar una mayor protección al viajero más allá de la que dispensa la DVCSVV, a salvo las disposiciones sobre validez, formalización o efectos de los contratos, y en la medida en que esos aspectos generales del derecho contractual no estén regulados en la Directiva, todo ello atendiendo a sus arts. $2.3^{76}$ y $4^{77}$.

En el ámbito de los viajes combinados, en el supuesto de que falte información precontractual, además de las sanciones administrativas que correspondan, procederá integrar el contrato conforme a la buena fe objetiva ${ }^{78}$, de manera que el empresario quedaría obligado por el contrato a todo lo que la otra parte hubiera podido razonablemente esperar como consecuencia de la ausencia o defecto de la información, sin perjuicio de que existan supuestos más graves en los que se

${ }^{76}$ La DVCSVV, "no afecta a las disposiciones generales del Derecho contractual nacional, por ejemplo a las normas sobre validez, formalización o efectos de los contratos, en la medida en que esos aspectos generales del Derecho contractual no estén regulados en la presente Directiva».

77 "Salvo que se disponga de otro modo en la presente Directiva, los Estados miembros no mantendrán ni establecerán, en su Derecho nacional, disposiciones contrarias a las establecidas en la presente Directiva, en particular disposiciones más o menos estrictas que den a los viajeros un nivel diferente de protección».

${ }^{78}$ Tal integración procedería también en el supuesto de considerar condiciones no incorporadas al contrato, conforme a los arts. 5 y 7 de la LCGC, las que «el adherente no haya tenido oportunidad real de conocer de manera completa al tiempo de la celebración del contrato", así como en caso de que se declare la nulidad de alguna de las cláusulas del contrato, previa realización de un juicio de abusividad por falta de transparencia. A la nulidad de una cláusula insertada en condiciones generales de la contratación, como consecuencia de un juicio de abusividad por su falta de transparencia, se refiere la STS 29.4.2015 (Cendoj: 28079110012015100275), acerca de las cláusulas suelo, con cita de SSTS 9.5.2013, 24.3.2015 y 25.3.2015, haciendo referencia a que la «doctrina jurisprudencial es aplicable no solamente a las cláusulas suelo objeto de tales procesos, sino a todas las que constituyan cláusulas no negociadas en contratos concertados con consumidores», señalando que en el caso "la cláusula... recibió un tratamiento secundario en la información suministrada al consumidor, hasta el punto de que no aparecía en el folleto de la oferta hecha a los mutualistas de Muface. En la escritura de préstamo hipotecario, la cláusula se ubicó entre una abrumadora cantidad de datos, dentro los cuales quedaba enmascarada y diluía la atención del consumidor; se encontraba ubicada en un lugar secundario de la reglamentación contractual, y no en un lugar destacado»... "No basta, por tanto, con que las condiciones generales puedan considerarse incorporadas al contrato por cumplir los requisitos previstos en el art. 5.5 de la Ley de Condiciones Generales de la Contratación. Es preciso que, además, sean transparentes, en el sentido de que el consumidor pueda hacerse una idea cabal de las consecuencias económicas y jurídicas que la inclusión de tal cláusula le supondrá». 
pueda llegar a la anulación del contrato por error o dolo. Además, si la falta de información ocasiona daños y perjuicios al consumidor, podrá reclamar los mismos, e incluso reducción de precio si se produce falta de conformidad ${ }^{79}$.

En el caso de que existiese la información precontractual, pero algún aspecto de la misma no fuera coincidente con lo efectivamente contratado, habría incumplimiento de los arts. 6 y 7.2 DVCSVV, tanto si el empresario no informó previamente al viajero de los cambios en la información previamente suministrada, como si habiéndole informado de las modificaciones de la información precontractual, no las hubiera sometido al acuerdo expreso del viajero. En estos casos se plantearía si el viajero habría de estar a lo previamente informado o a lo efectivamente contratado.

La DVCSVV ha tratado de garantizar la coherencia entre la información precontractual y las cláusulas del contrato, al reconocer el carácter vinculante de la información precontractual acerca de las principales características del viaje, y obligar a reproducir tal información en el propio contrato, para evitar contradicciones entre lo informado y lo contratado; y, en casos de modificaciones en la información inicialmente suministrada, exige que tales cambios sean informados antes de celebrarse el contrato, de forma clara, precisa y destacada, y que, además, hayan sido objeto de acuerdo expreso entre los contratantes ${ }^{80}$, para que el viajero cuando contrate sea plenamente consciente de los cambios habidos en la información inicialmente suministrada, correspondiendo al empresario la prueba del cumplimiento de estos requisitos. Como advertíamos se trata de requisitos cumulativos, de modo que faltando uno de ellos, el viajero podrá exigir lo que le sea más favorable, lo informado o lo contratado.

${ }^{79}$ Art. 14 DVCSVV.

80 Díaz Gómez, M. A., ob. cit., pág. 89. Infante Ruiz sostiene que: «La oferta, y publicidad prevalecerán siempre, salvo si expresamente se indican los cambios correspondientes en el documento en donde figura el contrato...». INFANTE RUIZ, F. J.: "La integración del contrato con el contenido de la publicidad..., ob. cit, pág. 206. En el mismo sentido Marín López, para el que: «... ha de tratarse de un pacto expreso, precisamente para que el comprador asuma la importancia el mismo y permita a su vez destruir la confianza generada previamente por la publicidad». MARín LóPEZ, M. J. Las garantías en la venta de bienes de consumo en la Unión Europea. La Directiva 1999/44/CE, y su incorporación en los Estados miembros, INC, Madrid, 2004, pág. 119. Propone SANTOS MoRón que se haga constar en el contrato el consentimiento del viajero a la modificación, para lo que sería necesario: "que tal cláusula apareciese de algún modo resaltada o destacada respecto al resto del contrato y sea particularmente firmada por el consumidor». Santos Morón, M. J., ob.cit, págs. 37 y 38. 
Por tanto, si en el contrato aparece alguna modificación respecto a la información precontractual inicial, que no hubiera sido informada al viajero de forma clara, comprensible y destacada, y con la debida antelación, aunque conste la aceptación por el viajero del clausulado contractual, consideramos que éste podrá exigir el cumplimiento de lo que le sea más favorable, ya que tal modificación puede haberle pasado desapercibida, pudiendo entenderse que contrató confiado en la información que tenía disponible al aceptar las cláusulas contractuales, siendo aplicables los arts. 1258 Cc y 61 y 65 TRLGDCU ${ }^{81}$. Esta conclusión se encuentra apoyada además, por lo dispuesto en el art. 23 DVCSVV, que garantiza al viajero que no va a quedar vinculado por ninguna cláusula contractual o declaración que suponga una renuncia o limitación directa o indirecta de los derechos conferidos a los viajeros por la presente Directiva o que tenga por objeto eludir su aplicación ${ }^{82}$, lo que le permitiría alegar que no quedará vinculado por cláusula alguna del contrato que le suponga una renuncia o limitación a lo que se establecía en la información precontractual de la que tenía constancia antes de contratar, y que la DVCSVV considera vinculante. Por otra parte, si el viajero tuvo conocimiento de los cambios en la información precontractual, pero tales cambios no fueron llevados al contrato, incumpliendo el empresario además el art. 7 DVCSVV, consideramos que el viajero podría exigir lo que le sea más favorable, al no haber acuerdo expreso en relación con tal modificación.

En el caso de la contratación on line de los viajes combinados, si se hubieran introducido modificaciones en la página web donde se recoge la información precontractual podrían pasar desapercibidas al consumidor que ya hubiera formado su voluntad sobre la primera versión, y días más tarde acude a la misma página web a cerrar la operación ${ }^{83}$. Por tanto, antes de contratar, habrá que advertir al viajero de las modificaciones realizadas en la información, ya destacándolas en la web con algún color, mayor tamaño de la tipografía o mediante una indicación que alerte de la modificación, ya introduciendo

81 En este sentido, SANTOS Morón, M. J., «El folleto o programa informativo...», ob.cit., pág. 37 .

82 Art. 23 DVCSVV

83 Para un estudio más detallado, CAVANILLAS MÚGICA, S. «Contratación on line de viajes combinados». Turismo y Comercio Electrónico: la promoción y contratación "on line» de servicios turísticos, Cavanillas MúGICA, S. (Dir.), 2001, págs. 153 a 164. 
la modificación en una página de paso obligado que dé lugar a la conformidad del contratante ${ }^{84}$.

La DVCSVV parte de que si previamente se han informado los cambios, y consta el acuerdo expreso, no se frustra la expectativa del viajero, si bien en ocasiones, pueden existir modificaciones respecto a la información inicial que el viajero consienta por mera tolerancia, ante la alternativa de no realizar el viaje, perdiendo días de vacaciones, habiendo incluso adquirido bienes para su uso durante el viaje... Por ello, consideramos muy importante que para que puedan ser oponibles al viajero modificaciones que incluso, puedan llegar a perjudicarle respecto de la información inicial, se valore en cada caso, si se han puesto en su conocimiento con suficiente claridad y antelación a la celebración del contrato, habiendo tenido margen para la reflexión.

No obstante todo lo anterior, el carácter vinculante de la información precontractual se diluye en cuanto la DVCSVV permite alterar no sólo la información precontractual, sino también las cláusulas del propio contrato en el supuesto del art. 11, que si bien comienza ordenando a los Estados que garanticen que, antes del inicio del viaje combinado, el organizador no pueda modificar unilateralmente las cláusulas del contrato de viaje combinado, con excepción del precio de conformidad con el artículo 10, permite introducir modificaciones cuando: «a) el organizador se ha reservado este derecho en el contrato; b) el cambio es insignificante, y c) el organizador informa al viajero de forma clara, comprensible y destacada en un soporte duradero». La utilización de conceptos indeterminados como «insignificante», es muy criticable, ya que deja la puerta abierta a distintas interpretaciones, pudiendo ser fuente de conflictos, y llegar a excluir algún aspecto previamente informado e incluso contratado.

${ }^{84}$ Serrano Escribano, S. «La Venta on Line de Viajes Combinados: Alcance de la Ley 34/2002, de 11 de Julio de Servicios de la Sociedad de la Información y Comercio Electrónico». V Congreso "Turismo y Tecnologías de la Información y las Comunicaciones» TuriTec, 2004, págs. 377-379. 
